
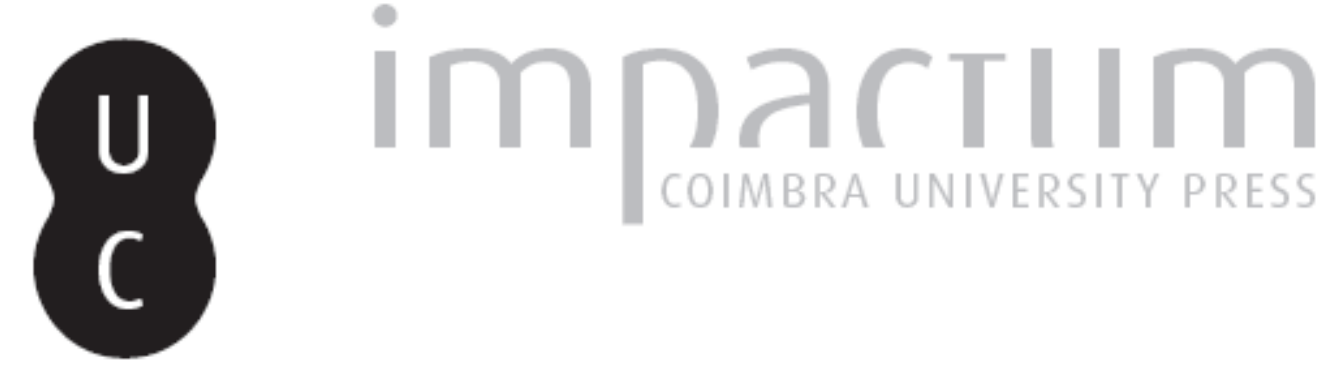

\title{
As Bucólicas de Virgílio e o epigrama 8.55 de Marcial: intertextualidade, mecenato e uma recusatio implícita
}

\author{
Autor(es): $\quad$ Cesila, Robson Tadeu \\ Publicado por: Sociedade Brasileira de Estudos Clássicos \\ URL \\ persistente: \\ URI:http://hdl.handle.net/10316.2/35802 \\ DOI: \\ DOI:http://dx.doi.org/10.14195/2176-6436_24_8
}

Accessed : $\quad$ 26-Apr-2023 12:44:17

A navegação consulta e descarregamento dos títulos inseridos nas Bibliotecas Digitais UC Digitalis, UC Pombalina e UC Impactum, pressupõem a aceitação plena e sem reservas dos Termos e Condições de Uso destas Bibliotecas Digitais, disponíveis em https://digitalis.uc.pt/pt-pt/termos.

Conforme exposto nos referidos Termos e Condições de Uso, o descarregamento de títulos de acesso restrito requer uma licença válida de autorização devendo o utilizador aceder ao(s) documento(s) a partir de um endereço de IP da instituição detentora da supramencionada licença.

Ao utilizador é apenas permitido o descarregamento para uso pessoal, pelo que o emprego do(s) título(s) descarregado(s) para outro fim, designadamente comercial, carece de autorização do respetivo autor ou editor da obra.

Na medida em que todas as obras da UC Digitalis se encontram protegidas pelo Código do Direito de Autor e Direitos Conexos e demais legislação aplicável, toda a cópia, parcial ou total, deste documento, nos casos em que é legalmente admitida, deverá conter ou fazer-se acompanhar por este aviso.

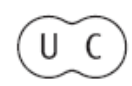




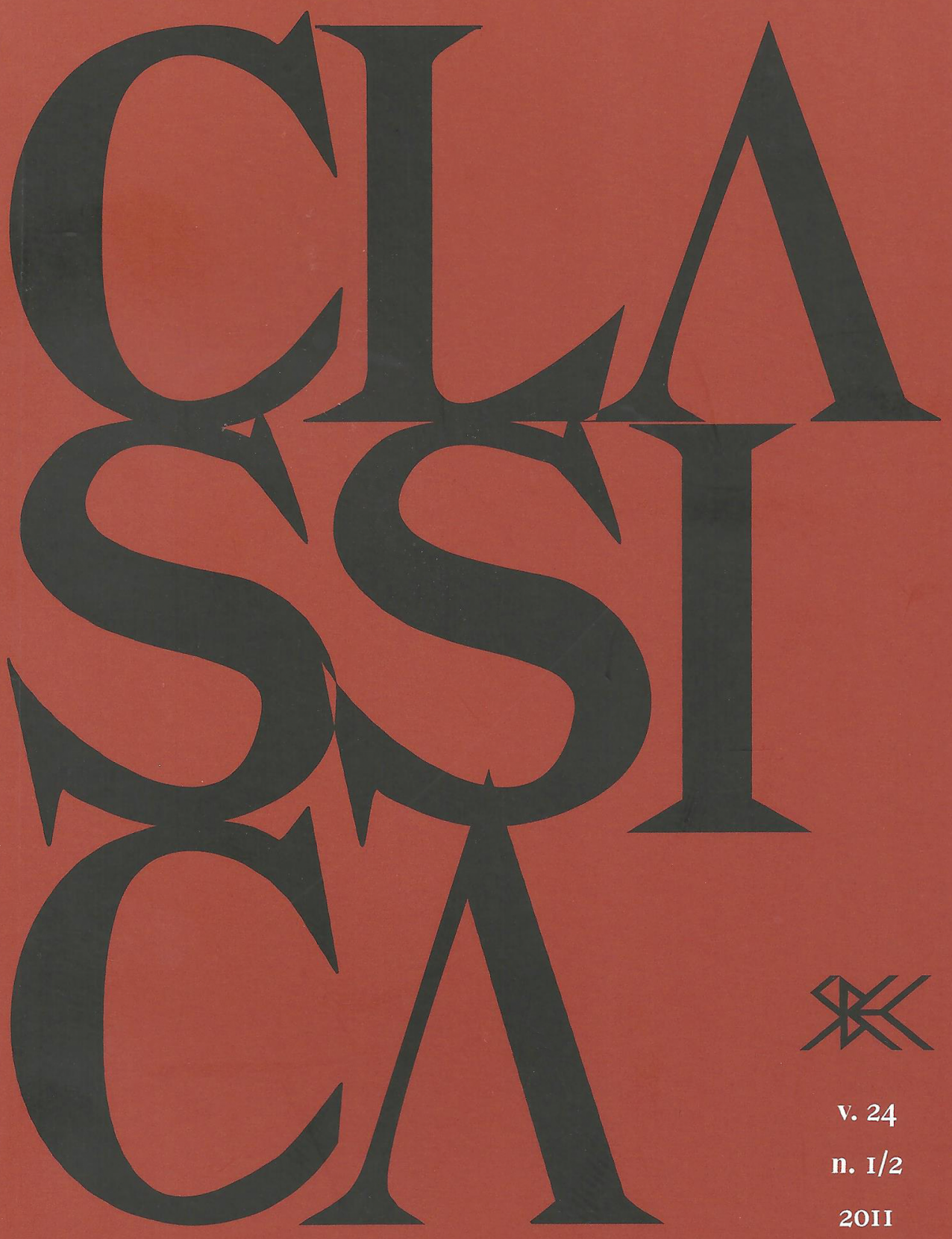




\title{
As Bucólicas de Virgílio e o epigrama 8.55 de Marcial: intertextualidade, mecenato e uma recusatio implícita
}

\author{
Robson TAdeu Cesila \\ Universidade de São Paulo \\ Brasil
}

Resumo. Este artigo analisa os fortes elementos intertextuais que relacionam o epigrama 55 do livro 8 de Marcial com as Bucólicas de Virgílio, especialmente as de número 1, 2 e 9. Incorporando esses elementos de forma e conteúdo trazidos dos poemas virgilianos, Marcial constrói, nesse habilidoso epigrama metapoético, uma "biografia" do poeta de Mântua muito útil na defesa da ideia da necessidade de apoio material aos escritores para o surgimento de grandes obras literárias; ao mesmo tempo, por meio de uma recusatio que fica implícita nos últimos versos do epigrama, Marcial aborda a questão dos gêneros poéticos e justifica, como em tantos outros passos de sua obra, a sua opção pela poesia ligeira.

Palavras-chave. Marcial; epigrama; Virgílio; Bucólicas; intertextualidade; mecenato; recusatio.

Otia da nobis, sed qualia fecerat olim Maecenas Flacco Vergilioque suo - Marcial, Epigramas, 1.107.3-4

Um tema que frequenta assiduamente a obra do epigramatista Marcial (c. 38 d.C. - c. 104) é a queixa a respeito das dificuldades da vida de poeta: a incômoda condição de "cliente", a pouca valorização dessa "profissão" em relação a ocupações mundanas e servis (mais bem remuneradas e valorizadas, segundo ele), a falta de apoio material - e a avareza - dos patronos da época, e o prejuízo que as obrigações de cliente trariam à atividade poética. A lista de epigramas que tocam, com maior ou menos

Email: robson.cesila@ig.com.br

Professor de Língua e Literatura Latina na Faculdade de Filosofia, Letras e Ciências Humanas (DLCV/FFLCH/USP).

O presente artigo constitui a versão ampliada de texto apresentado sob a forma de comunicação no XVIII Congresso Nacional de Estudos Clássicos (Rio de Janeiro, 17-21 outubro de 2011). A participação no evento contou com financiamento da FAPESP. 
ênfase, nesse tema, é extensa: 1.70 e 107; 3.4, 7, 14, 36, 38, 46 e.60; 5.16; $8.55 ; 9.73,10.9,58,70,74$ e $76 ; 11.3,24$ e 108 ; e 12.68 .

Em algumas dessas peças, Marcial compara o patronato de sua época àquele que existia na era de Augusto, quando ricas figuras políticas como Mecenas, Asínio Polião, Messala Corvino e o próprio imperador sustentavam artistas e escritores por meio de dinheiro, bens e presentes, proporcionando-lhes, segundo o epigramatista, o otium necessário (cf. 1.107.3) à criação artística e literária. Temos esse confronto com o passado nos epigramas 1.107, que cita Mecenas, Virgílio e Flaco (Horácio), 11.3, que cita Mecenas, e 12.3, que cita Mecenas, Marão (Virgílio), Flaco (Horácio) e Vário. Mas nenhum epigrama é mais exemplar, nesse sentido, do que 8.55 , em que o epigramatista, por meio de uma série de alusões às Bucólicas de Virgílio, constrói uma divertida e tendenciosa biografia do poeta de Mântua, na qual atribui toda a grandeza e talento de Virgílio à proteção e patrocínio recebidos de Mecenas. ${ }^{1}$ Vejamos:

Temporibus nostris aetas cum cedat auorum creuerit et maior cum duce Roma suo, ingenium sacri miraris desse Maronis nec quemquam tanta bella sonare tuba.

Sint Maecenates, non derunt, Flacce, Marones,

Vergiliumque tibi uel tua rura dabunt.

Ingera perdiderat miserae uicina Cremonae

flebat et abductas Tityrus aeger oues:

risit Tuscus eques paupertatemque malignam

reppulit et celeri iussit abire fuga.

"Accipe diuitias et uatum maximus esto;

tu licet et nostrum" dixit "Alexin ames."

Adstabat domini mensis pulcherrimus ille

marmorea fundens nigra Falerna manu,

et libata dabat roseis carchesia labris

quae poterant ipsum sollicitare Iouem.

Excidit attonito pinguis Galatea poetae

Thestylis et rubras messibus usta genas:

protinus Italiam concepit et arma uirumque,

qui modo uix Culicem fleuerat ore rudi.

Quid Varios Marsosque loquar ditataque uatum

nomina, magnus erit quos numerare labor?

${ }^{1}$ Cf. M. Citroni, 'Marziale' in Della Corte, F. (org.), Enciclopedia Virgiliana 3, Roma, Instituto dell'Enciclopedia Italiana, 396-400, 1987, p. 398. O presente artigo deve muitos dos intertextos aqui analisados a esse verbete de Citroni. 


\section{Ergo ero Vergilius, si munera Maecenatis} des mihi? Vergilius non ero, Marsus ero.

Nossa época supera a de nossos avós e engrandeceu-se Roma com seu chefe, mas te espanta que falte o gênio de um Marão e alguém que as guerras soe em igual tuba.

Se houver Mecenas, Flaco, abundarão Marões, e um Virgílio vão dar-te até teus campos.

Perdera as glebas perto da infeliz Cremona Títiro, a grei roubada lamentando; sorriu o cavaleiro etrusco e a má pobreza repeliu e mandou fugir ligeira.

"Toma estas posses - disse - e sê o maior dos vates!

E até permito que ames meu Aléxis!"

(Lindíssimo, este à mesa do senhor servia, mão marmórea a verter negro Falerno; copos por róseos lábios provados lhe dava, lábios que ao próprio Jove atrairiam.)

Pasmo, o poeta esqueceu a rude Galateia e Téstilis de tez rubra das messes, e logo a Itália e as armas e o varão compôs quem rude a mosca a custo antes chorara.

Por que Vários e Marsos citar e dos ricos vates os nomes, rol tão trabalhoso?

Serei, pois, um Virgílio, se os dons de Mecenas me dás? Não um Virgílio, mas um Marso. ${ }^{2}$

Os dois dísticos iniciais promovem sutilmente o elogio do imperador da época de Marcial (cf. cum duce ... suo, 2): se a Roma do presente, governada por Domiciano, supera a Roma do passado (a Roma de Augusto, especialmente) e se tornou muito mais importante e imponente que ela, por que não há no presente um poeta tão grandioso quanto o que havia na era augustana? Por que não há na Roma hodierna um Virgílio que cante tão divinamente os feitos guerreiros (cf. bella, 4) da Roma de Domiciano, se esses são até superiores aos feitos de Augusto? ${ }^{3}$ A resposta é dada pelo próprio poeta, em dois versos provocadores e memoráveis: se ainda exis-

\footnotetext{
${ }^{2}$ A tradução, que usa dodecassílabos para o hexâmetro e decassílabos para o pentâmetro (sempre com a sexta sílaba forte, com acentuações secundárias variadas nas outras sílabas), é de nossa autoria.

${ }^{3}$ Notem-se as aliterações e assonâncias desses quatro versos: ... Aetas Cum Cedat Auorum (1), Creuerit ... Cum duCe (2), Miraris ... Maronis (3), TanTa ... Tuba (4).
} 
tissem pessoas como o Gaio Mecenas da áurea época augustana, haveria Virgílios aos montes, até mesmo em locais onde não se esperaria encontrá-los, isto é, entre os rústicos e deseducados camponeses. ${ }^{4} \mathrm{O}$ dístico, de grande sonoridade, é enfático e sintetiza o pensamento, que o poeta desenvolverá no restante do poema, de que é necessário apoio material para que grandes obras venham a ser produzidas: notem-se as aliterações nasais dos nomes próprios MaeceNates ... MaroNes - que vêm, no hexâmetro, associados, demonstrando os dois pólos da relação de patronato - e as presentes em Vergilium ... Vel e Tibi ... Tua ... dabunT, no pentâmetro. ${ }^{5}$ Além disso, a solenidade e a gravidade proporcionadas pelo uso de espondeus em todos os pés do hexâmetro (com exceção, claro, do dátilo obrigatório do quinto pé) dão, a nosso ver, força de verdade incontestável à afirmação de que existirão Marões se existirem Mecenas; o esquema métrico-rítmico do pentâmetro dá continuidade a essa intensificação, mas, desta vez, com o uso exclusivo de dátilos, mesmo nas posições opcionais dos dois primeiros pés:

\section{Sīnt Māe/cēnā/tēs, nōn/ dērūnt,/ Flāccě, Mă/rōnēs, Vērgūlı̌/ūmquě tī/bīi/ uēl tǔă/ rūră dă/būnt. ${ }^{6}$}

Segue-se, então, a pequena estória contada por Marcial sobre a vida de Virgílio, estória essa baseada em interpretações biografistas das Bucólicas já correntes à época do epigramatista. $\mathrm{O}$ trecho todo (7-20) é repleto de ecos

\footnotetext{
${ }^{4}$ Mas tua rura poderia também ser uma referência à própria origem rural de Virgílio, que nascera nas imediações rurais de Mântua, na Gália Cisalpina. Como aponta P. S. de Vasconcellos (Efeitos Intertextuais na Eneida de Virgílio, São Paulo, Humanitas, 2001, p. 20, n. 14), a origem rústica do poeta também é mencionada pelo personagem Evângelo das Saturnais de Macróbio (5.2.1), em trecho em que, criticando Virgílio, pergunta provocativo: Vnde enim Veneto rusticis parentibus nato, inter siluas et frutices educto, uel leuis Graecarum notitia litterarum? ("Pois como um vêneto, filho de pais camponeses, criado entre florestas e arbustos, poderia ter conhecimento, por mais vago fosse, das letras gregas?"). A tradução é de Vasconcellos (ibid.).

${ }^{5}$ Tua rura dabunt pode ser evocação de Buc. 1.46: Fortunate senex, ergo tua rura manebunt! ("Velho feliz, pois teus campos permanecerão teus!"). Trata-se de uma fala de Melibeu a Títiro, que, ao contrário do primeiro, conseguiu conservar suas propriedades diante dos confiscos feitos por Otávio

${ }^{6} \mathrm{O}$ Flaco a quem o poeta se dirige é provavelmente o mesmo indivíduo que aparece em muitos outros epigramas (cf. 1.57 e 59, 4.42, 7.87, 8.45, 9.55 e 90, 10.48, 11.80 etc.), a partir dos quais se infere que era um rico cidadão e amigo de Marcial. Trata-se, segundo P. White (The friends of Martial, Statius, and Pliny, and the dispersal of patronage, HSPh 79, 265-300, 1975, p. 270), da segunda personalidade mais citada no corpus do poeta, atrás apenas do imperador Domiciano.
}

${ }^{7}$ Citroni, p. 398. 
das Bucólicas, mas, antes de apreciarmos mais detidamente esses intertextos, acompanhemos, em linhas gerais, o "enredo" construído por Marcial.

Virgílio, equiparado ao pastor Títiro, perdera suas terras, herança paterna, perto de Mântua, cidade vizinha de Cremona, na então Gália Cisalpina, norte da Itália (7). Junto das terras, perdera, obviamente, os rebanhos que nelas havia (8). Mas Mecenas (chamado o "etrusco cavaleiro", por descender de uma família equestre de Arrécio, a moderna Arezzo, na Etrúria $^{8}$ ) veio em socorro de Virgílio-Títiro e lhe forneceu bens materiais que lhe permitiriam o ócio necessário para se tornar o maior de todos os poetas (9-11). Também lhe ofereceu seu jovem escravo, o belo escanção Aléxis (12-16), com quem o poeta teria ficado de tal forma encantado que esquecera suas antigas paixões, a rude Galateia e Téstilis, de rosto afogueado e queimado devido ao trabalho na colheita (17-18). Só assim, com o apoio do patrono, fora possível, a quem há pouco compusera o Culex, obra menor, produzir a grande e eternamente admirada Eneida (19-20).

$\mathrm{Na}$ verdade, a sequência de fatos descrita por Marcial e as alusões feitas às éclogas virgilianas permitem a equiparação de Virgílio não só a Títiro - uma equação já presente, como lembra Citroni ${ }^{9}$, em Calpúrnio Sículo, imitador de Virgílio da época de Nero -, mas também a outros personagens das Bucólicas, como Melibeu, Menalcas e Córidon. As éclogas às quais Marcial alude mais fortemente são a 1, a 2 e a 9.

As de número 1 e 9 têm importância especial para nossa análise porque são justamente as duas da coleção virgiliana que têm por tema o confisco de terras da Gália Cisalpina e a sua distribuição, como prêmio, aos veteranos do exército de Otávio, após a vitória deste e de Marco Antônio, em 42 a.C., sobre as forças comandadas por Cássio e Bruto, assassinos de Júlio César. Na Buc. 1, dois pastores, Títiro e Melibeu, conversam sobre os confiscos, sendo que o primeiro, um velho escravo há pouco libertado, diz ter conservado suas terras graças à intervenção de "um deus", com quem foi ter na cidade de Roma, e que é tradicionalmente identificado com Otávio, futuro imperador Augusto (1.6-10 e 40-5). Já Melibeu não teve a mesma sorte e terá de partir para outras paragens, pois suas terras foram distribuídas aos soldados (1.11-16 e 64-78). Na Buc. 9, os pastores Méris e Lícidas, a caminho da cidade, comentam sobre o confisco das terras de Menalcas, vizinho ou senhor de Méris, em favor dos veteranos de Otávio. Lícidas menciona o rumor de que Menalcas teria conservado suas posses como paga por seu talento poético, fato que é desmentido por Méris

${ }^{8}$ Cf. Hor. Carm. 1.20 .5 e 3.16.20, e Prop. 4.8.1.

${ }^{9}$ P. 398. 
(9.2-16). Tanto este último como Menalcas e Lícidas são poetas, embora Lícidas não acredite em seu próprio talento (9. 32-6); assim, na metade final da écloga, Méris e Lícidas, enquanto caminham, vão declamando versos de Menalcas e do próprio Méris.

Marcial, nos versos 7-8 de seu epigrama, associa Títiro a Virgílio. Uma vez que a Buc. 1, como acabamos de ver, trata do confisco de terras dos colonos e traz, como o personagem que sofre essa sina, o pastor $\mathrm{Ti}$ tyrus, é evidente que o epigrama está dialogando intertextualmente com essa Bucólica. Porém, não devemos esquecer que o próprio Virgílio se intitula "Títiro" na Buc. 6, versos 4-6..$^{10}$ Além disso, um pastor com o mesmo nome aparece em outras quatro éclogas, ainda que com papel secundário (cf. Buc. 3.20 e 96, 5.12, 8.55 e 9.23-4). Pode-se dizer, portanto, que o epigrama também dialoga, de alguma forma, com essas outras Bucólicas em que há um pastor chamado Títiro.

Entretanto, como aponta Citroni ${ }^{11}$, Marcial utilizou, em seu verso 7, palavras não da Buc. 1, mas da 9: miserae uicina Cremonae retoma palavras de versos de Menalcas citados por Méris no verso 28 dessa écloga:

Moeris:

Immo haec quae Varo, necdum perfecta, canebat:

"Vare, tuom nomen, superet modo Mantua nobis,

Mantua uae miserae nimium uicina Cremonae, cantantes sublime ferent ad sidera cycni." (Buc. 9.26-9)

Méris:

Ou este que, incompleto, a Varo foi cantado:

"Varo, o renome teu, se Mântua mantivermos, de Cremona infeliz, ah!, Mântua tão vizinha, os cisnes cantarão sublime até os astros".’’12

O Varo a quem os versos de Menalcas, reportados por Méris, são dedicados seria Públio Alfeno Varo, consul suffectus em 39 a.C. e integrante

\footnotetext{
${ }^{10}$ E se associa a ele na sphragís das Geórgicas (4.559-66): Virgílio fala do ócio de que desfrutou em Nápoles quando compunha as Bucólicas, ócio que podemos associar com aquele de que desfruta Títiro em Buc. 1.6 (deus nobis haec otia fecit). Além disso, Virgílio diz, no trecho das Geórgicas, que "compôs se divertindo" (lusi) as Bucólicas (carmina qui lusi pastorum, 565); Títiro, na Buc. 1, diz que um deus lhe permitiu "compor se divertindo" (ludere), em seu agreste cálamo, o que bem entendesse (ludere quae uellem calamo permisit agresti, 10). Agradeço ao prof. Paulo Sérgio de Vasconcellos por essa observação. ${ }^{11}$ P. 398.

${ }^{12}$ Tradução de Raimundo Barbosa Nonato de Carvalho (Virgílio, Bucólicas, Belo Horizonte, Crisálida, 2005, p. 85).
} 
da comissão responsável por confiscar as terras da Cisalpina a serem doadas aos veteranos ${ }^{13}$. Menalcas diz que o nome de Varo será imortalizado pela poesia, caso Mântua seja poupada das expropriações.

Note-se que, apesar de não retomar da bucólica o nome da cidade de Virgílio (Mantua) - a qual substitui pelo genérico iugera ("jeiras", glebas") ${ }^{14}$ - nem nimium, intensificador de uicina, Marcial mantém as outras três palavras em sua forma idêntica. ${ }^{15}$ Duas delas, inclusive, ocupam, no hexâmetro de Marcial, a mesma posição em que se encontravam no hexâmetro virgiliano, formando o dátilo e o espondeu do quinto e sexto pés e deixando a sílaba $u i$ - no espondeu do quarto pé:

\section{Māntǔă/ uāe mǐsě/rāe nĭmǐ/ūm ūi/cīnă Crě/mōnāe! (Virgílio)}

\section{Iūgĕră/ pērdĭdě/rāt mǐsě/rāe uī/cīnă Crě/mōnāe (Marcial)}

$\mathrm{Na}$ verdade, não há grande diferença de sentido nesses versos, uma vez que Mantua é usada metonimicamente para designar as terras que teriam sido perdidas por Virgílio-Menalcas, possivelmente uma herança paterna, dado que essa cidade era a terra natal do poeta. Mantua equivale, portanto, a iugera. Quanto à adjetivação de Cremona como "mísera", "infeliz" (miserae), deve-se ao fato de que também sofrera com as expropriações, a exemplo de grande parte da Gália Cisalpina. ${ }^{16}$

Então, manipulando com certa liberdade o material imitado, Marcial equipara Virgílio, a um só tempo, a Títiro - através da menção direta e explícita de seu nome e da retomada da situação de confisco de terras presente na Buc. 1 - e a Menalcas - pela retomada do material verbal da Buc. 9 e da mesma situação de confisco de terras, sofrida por Menalcas nessa écloga. ${ }^{17}$

${ }^{13}$ E. Badian e T. Honoré, ${ }^{3}$ OCD, s.v. Alfenus Varus, Publius, p. 63.

${ }^{14}$ Mais precisamente, a jeira (iugerum) era, entre os romanos, uma medida de área, usada sobretudo nas medições agrárias. Correspondia à quantidade de terreno que poderia ser arada por uma junta de bois no espaço de um dia de trabalho (cf. J. E. Sandys (ed.), $A$ Companion to Latin Studies, Cambridge, Cambridge University Press, ${ }^{3} 1943$, p. 438).

${ }^{15}$ Não se pode negar, porém, que as substituições operadas enfraquecem o efeito intensificador proporcionado pela profusão de nasais do verso virgiliano, nasalidade essa tão adequada ao tom lamentoso do verso: MaNtua uae Miserae NiMiuM uiciNa CreMoNae. ${ }^{16}$ Élio Donato, comentador de Virgílio que viveu no século IV de nossa era, diz, no prefácio às Bucólicas, que inicialmente só o território de Cremona fora expropriado; porém, como ele não fora suficiente para a distribuição aos veteranos, as terras de Mântua também foram confiscadas (apud Della Corte, F. (org.), Enciclopedia Virgiliana 5**, p. 439). ${ }^{17}$ Marcial não usa, como se vê, o nome "Menalcas" da Buc. 9, mas apenas associa versos desse personagem ao Títiro da Buc. 1. Títiro e Menalcas, das duas bucólicas, são fundidos 
Mas tornemos a equação um pouco mais complexa. Os mesmos dois versos de Marcial que estamos observando permitem uma terceira associação com um personagem das Bucólicas.$^{18} \mathrm{O}$ epigramatista diz, no verso 8 , que Títiro lamentava, triste (aeger), o fato de suas ovelhas lhe terem sido arrebatadas (flebat ... abductas ... oues). Na Buc. 1, é Melibeu quem está triste (aeger, 13), pois, ao contrário de Títiro, que tivera o auxílio de "um deus", Melibeu perdera suas terras, e está levando o rebanho para outras paragens:

Meliboeus:

Non equidem inuideo, miror magis: undique totis usque adeo turbatur agris! En ipse capellas protinus aeger ago; hanc etiam uix, Tityre, duco: hic inter densas corylos modo namque gemellos, spem gregis, a! silice in nuda connixa reliquit. (Buc. 1.11-15)

\section{Melibeu:}

Não te invejo, porém, me espanto: em toda parte, o campo é perturbado! Eu mesmo as minhas cabras triste tanjo; esta, a custo, ó Títiro, conduzo: ainda agora, sob densa aveleira, gêmeos, esperança da grei, pariu na pedra nua. ${ }^{19}$

Apesar da substituição de capellas (v. 12 de Virgílio) por oues (v. 8 do epigrama) e da ligeira diferença de sentido nos dois trechos (Melibeu, na écloga, parece ter perdido apenas suas terras, não seu rebanho, que está levando para outras paragens; Títiro, no epigrama, perdeu tanto suas terras quanto suas ovelhas), ambos os personagens sofreram alguma perda e estão tristes, aeger. Outros marcadores da alusão nas passagens confrontadas podem ser o particípio abductas de Marcial (8), que evoca o verbo cognato duco do verso 13 da Bucólica $^{20}$; o uso do nome próprio nos dois versos (Tityre em Virgílio, Tityrus em Marcial); e a assonância inicial do /a/ em Abductas ... Aeger (v. 8 do epigrama), que evoca o mesmo efeito sonoro presente em Aeger Ago do verso 13 de Virgílio.

pelo epigramatista num só personagem, nomeado como "Títiro". Mas vale ressaltar que o nome Menalcas surge também nas Bucólicas 2, 3, 5 e 10, embora não se trate, em nenhuma delas, do tema da expropriação de terras. Nos poemas 3 e 5, Menalcas é um dos poetaspastores envolvidos no certame amebeu que estrutura as duas éclogas. Nos outros dois poemas, 2 e 10, Menalcas é um jovem pastor e personagem secundário, apenas mencionado.

${ }^{18}$ Cf. Citroni, p. 398.

${ }^{19}$ Tradução de Raimundo Barbosa Nonato de Carvalho (p. 13).

${ }^{20}$ Cf. também Buc. 2.41-3: capreoli ... abducere. 
Assim, ao aplicar a Títiro elementos que, na Buc. 1, dizem respeito a Melibeu, Marcial funde num só esses dois personagens virgilianos; consequentemente, se retomarmos o que dissemos acima sobre a fórmula na qual o próprio Virgílio é equiparado a Títiro e a Menalcas, a equação construída pelo epigramatista é agora tripla: Virgílio $=$ Títiro + Menalcas + Melibeu. $^{21}$

Prossigamos a análise dos outros versos de Marcial. Mecenas, o cavaleiro etrusco, ri bondosamente e manda embora a maligna pobreza que afligira Virgílio-Títiro após a perda de suas terras e rebanhos (8.9-10). Oferece-lhe então riquezas (11), além de seu belo escravo Aléxis, agradável consolo ao poeta-pastor entristecido (12). Aqui, uma terceira Bucólica entra em cena, a Buc. 2, na qual o pastor Córidon arde de amor pelo belo adolescente Aléxis e é por ele desprezado. Marcial parece ter se inspirado já nos primeiros versos da écloga:

Buc. 2.1-2

Formosum pastor Corydon ardebat Alexim, delicias domini: nec, quid speraret habebat.

Córidon, um pastor, pelo formoso Aléxis, delícias do seu dono, em desespero ardia-se. ${ }^{22}$

Note-se que o pulcherrimus (v. 12 de Marcial) retoma semanticamente o formosum de Virgílio e que ambos os poetas destacam que o escravo pertencia ao senhor (domini) do pastor. Percebe-se que domini, do verso 2 de Virgílio, é retomado sem alteração por Marcial (13), que o utiliza no mesmo caso (genitivo) e na mesma posição do verso, formando o dátilo do segundo pé e metade do espondeu do terceiro:

dēlǐcǐ/ās dŏmǐ/nĭ: nēc,/ quīd spē/rārĕ, hă/bēbăt. (Virgílio)

Ādstā/bāt dŏm̌̌/nī mēn/sīs pūl/chērrǐmŭs/ îllě. (Marcial)

${ }^{21}$ Lembremos ainda que um pastor de nome Melibeu surge em outras três Bucólicas (3, 5 e 7); porém, como Marcial, a exemplo do que fizera com a figura de Menalcas, não utiliza o nome "Melibeu", mas sim, atribui as características deste a Títiro, não vale a pena nos determos sobre esses três poemas. Basta mencionar que, nas Buc. 3 e 5, Melibeu é um pastor e figura secundária. $\mathrm{Na} B u c$. 7, o personagem é um pastor que presencia uma competição poética entre Córidon e Tírsis. Em nenhuma das três éclogas está presente o tema do confisco de terras dos colonos.

${ }^{22}$ Tradução de Raimundo Barbosa Nonato de Carvalho. 
A extrema brancura da pele de Aléxis é outro dado retomado pelo epigramatista, que nos apresenta, no verso 14 , o jovem escravo a servir à mesa de seu senhor, enchendo os copos com sua mão branca como o mármore (marmorea). Veja-se este trecho da mesma Bucólica, em que Córidon questiona a si mesmo sobre se vale a pena o amor de tão esquivo jovem:

\section{Nonne fuit satius tristis Amaryllidis iras atque superba pati fastidia? nonne Menalcam, quamuis ille niger, quamuis tu candidus esses? (Buc. 2.14-16)}

Melhor não era, ira amara de Amarílis, seu soberbo desdém, sofrer? Ou de Menalcas, embora ele seja um negro, e tu tão branco? ${ }^{23}$

Virgílio contrasta (16) a brancura (candidus) de Aléxis com a morenice (niger) de Menalcas (aqui, este nome designa um outro adolescente). Marcial mantém a característica alva de Aléxis, mas constrói o contraste não com outro adolescente, mas sim com o vinho Falerno que está sendo servido pelo escanção: se a sua mão é marmorea, o vinho é niger (14). ${ }^{24}$

O que se tira dessa breve análise das alusões de Marcial à Buc. 2 é que o epigramatista, embora de novo atribua a Títiro um elemento que diz respeito a outro personagem das Bucólicas (a saber, atribui a Títiro a paixão que Córidon tinha por Aléxis), está agora equiparando Virgílio a

\footnotetext{
${ }^{23}$ Idem.

${ }^{24}$ Contribuem para reforçar o contraste a colocação, nas extremidades do verso, de cada uma das palavras do sintagma marmorea manu, e as evidentes aliterações em /m/ (MarMorea ... Manu), /n/ (fuNdeNs Nigra falerNa maNu) e /f/ (Fundens ... Falerna). As próprias líquidas (maRmoRea ... nigRa faleRna), que continuarão nos versos 15-16 (Libata ... caRchesia LabRis/ quae poteRant ipsum soLLicitaRe Iouem) contribuem na criação de um clima de amenidade e brandura adequado a versos que falam de um jovem escravo objeto de paixão amorosa. No verso 14 do epigrama, é interessante a própria disposição dos termos possuidores de aliteração inicial: o sintagma marmorea manu "envolve" fundens nigra Falerna, representando graficamente a ideia das brancas mãos do escravo a segurar, envolver os recipientes de vinho Falerno; fundens Falerna, por sua vez, "envolve" o adjetivo nigra. Poderíamos representar a disposição desse verso com o seguinte esquema: ABCBA. Observem-se também os efeitos da disposição das palavras no verso 15: roseis ... labris "envolvem" carchesia, como se se criasse a imagem, no desenho gráfico do verso, dos dois lábios do escravo (representados pelas palavras roseis e labris, separadas) a provar os copos (carchesia) de vinho antes de servir a seu senhor. O carchesium era um vaso de beber, provido de asas, que, mais largo embaixo, ia se estreitando em direção à parte superior $\left({ }^{14} O L D\right.$, s.v. carchesium, 1, p. 276).
} 
Córidon ${ }^{25}$, e aí chegamos ao último termo de nossa equação: para Marcial, Virgílio $=$ Títiro + Menalcas + Melibeu + Córidon.

Ainda sobre a Buc. 2 e as figuras de Córidon e Aléxis, importa lembrar que, em Virgílio, o segundo não é apresentado, em momento algum, como escanção, como ocorre em Marcial. Tanto nesta como nas outras duas Bucólicas que citam Aléxis, este é apenas o jovem escravo por quem Córidon é apaixonado (cf. Buc. 5.86 e 7.53-6). ${ }^{26} \mathrm{O}$ texto de Marcial é, segundo Citroni, a mais antiga fonte que confere ao escravo Aléxis das $B u$ cólicas o papel de escanção (as outras referências, posteriores, teriam por fonte o próprio epigrama), além de ser o primeiro texto que traz o dado de que o escravo teria sido um presente dado a Virgílio por um de seus patronos (para Marcial, Mecenas; para todos os outros comentadores, Asínio Polião). ${ }^{27}$ Mas a leitura biografista das Bucólicas que identificava Córidon a Virgílio, e Aléxis ao escravo que teria sido dado de presente ao poeta, já gozava de crédito à época do epigramatista e seria mesmo anterior a ele. ${ }^{28}$

O papel de escanção que Marcial confere a Aléxis e a afirmação, do verso 16, de que o escravo era tão belo que poderia seduzir o próprio Júpiter também nos permitem identificar, na passagem, uma alusão a um passo homérico. Na Ilíada, 20.199-258, Eneias, prestes a se bater com Aquiles, descreve a descendência da casa de Dárdano, de que o herói troiano era originário. Nos versos 230-5, menciona Ganimedes, um dos três filhos de Trós:

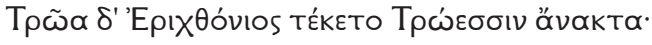

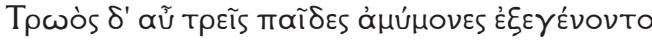

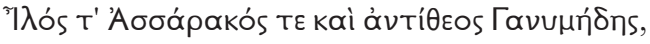

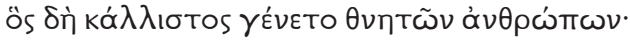

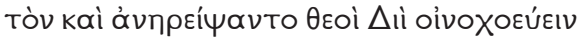

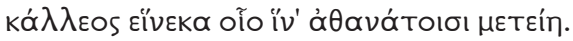

\footnotetext{
${ }^{25}$ Interpretação biografista que já gozava de crédito, segundo Citroni (p. 398), à época de Marcial.

${ }^{26}$ Sendo a função de escanção estranha ao cenário campestre do gênero bucólico, o puer, nesse tipo de poesia, embora tenha a função de amante, não pode ter a de escanção. Diferentemente, na poesia amatória de cenário urbano (seja ela lírica, elegíaca ou epigramática), o puer ministra o vinho aos convivas e ao amante. Devo essa observação ao prof. João Angelo Oliva Neto, a quem agradeço.

${ }^{27}$ Citroni, p. 398.

${ }^{28}$ Id. Ibid.. Acrescentemos que, no corpus de Marcial, Aléxis surge em outros cinco poemas. Em 5.16 e 8.73, há novamente referência ao fato de o escravo ser amante de Virgílio e de ter sido doado ao poeta por um de seus protetores; em 7.29, há apenas a menção a Aléxis como escravo e amante de Virgílio, sem outras informações; em 6.68 e 8.63, Aléxis surge, genericamente, como um nome típico de escravo amado por poetas, mas, ainda assim, pode-se reconhecer a alusão ao personagem das Bucólicas.
} 


\section{(...) Erictônio gerou Trós,}

rei dos Tróicos, que teve três filhos imáculos, Ilo, Assáraco e - par-dos-deuses - Ganimedes, que foi, entre os mortais, o mais belo: os Celestes o raptaram, a fim de que, por sua beleza, servisse o vinho a Zeus, restando entre os eternos. ${ }^{29}$

Ganimedes, na mitologia grega, era de tão incrível beleza que teria cativado o pai dos deuses, o qual, sob a forma de uma águia, o teria raptado e levado para o Olimpo, onde fizera do jovem seu amante e escanção. Marcial, embora sem nomear Ganimedes, iguala à beleza deste a de Aléxis, dizendo que o belo escravo dado a Virgílio também poderia seduzir o próprio Júpiter. O Ganimedes homérico é, aliás, o paradigma, na tradição mítico-literária, do jovem escanção de grande beleza.

Nos versos 17-18, o epigramatista diz que Títiro-Virgílio, encantado com a beleza de Aléxis, esqueceu suas paixões femininas, Galateia e Téstilis. A primeira é qualificada, no epigrama, como pinguis, "rude", "grosseira" (também poderia significar "gorda", "bem nutrida"), termo comum nas Bucólicas, mas nunca aplicado, nesses poemas, a seres humanos. Galateia é personagem de duas das éclogas (cf. 1.30-1 e 3.64-5 e 72-3), sendo que em ambas ela é uma jovem, amante de Títiro na Buc. 1 e de Dametas na Buc. 3. ${ }^{30}$

Quanto a Téstilis, é personagem da Buc. 2, e aqui os intertextos se mostram um pouco mais ricos. Construindo, nessa Bucólica, uma interessante atmosfera que associa o calor do dia e o calor da paixão, Virgílio nos apresenta o pastor Córidon a sofrer pelo amor não correspondido do belo escravo Aléxis; enquanto tudo ao redor busca a calma, o frescor e o repouso, o infeliz enamorado anda sob o sol ardente em busca do cruel adolescente:

Buc. 2.6-13

"O crudelis Alexi, nihil mea carmina curas?

Nil nostri miserere? mori me denique coges.

Nunc etiam pecudes umbras et frigora captant;

nunc uiridis etiam occultant spineta lacertos.

Thestylis et rapido fessis messoribus aestu alia serpullumque herbas contundit olentis. At mecum raucis, tua dum uestigia lustro, sole sub ardenti resonant arbusta cicadis."

${ }^{29}$ Tradução de H. de Campos (Iliada de Homero 2, São Paulo, Arx, 2002, p. 305).

${ }^{30}$ Em Buc. 8.37 e 9.39, não se trata de pastora, mas da ninfa Galateia, personagem mitológica. 


\begin{abstract}
"Não escutas, cruel Aléxis, os meus cantos?
Não tens pena de mim? Me forças a morrer.

Agora o gado goza o frescor de uma sombra;

agora o espinhal verde lagarto oculta,

e Téstiles prepara, para os ceifeiros exaustos

pelo estio voraz, alho e serpilho olentes.

Mas, enquanto persigo o teu rastro, cigarras

roucas, sob sol ardente, em arbustos ressoam." ${ }^{31}$
\end{abstract}

Téstilis, como se vê, surge no verso $10^{32}$, a preparar unguentos para mitigar os efeitos do calor ardente sobre os exaustos ceifadores, os trabalhadores da colheita (messores). Não é difícil ver que messibus, em Marcial, evoca o messoribus de Virgílio, e que, a exemplo deste, aquele também iniciou seu verso com Thestylis et. Mantém-se igualmente uma certa aliteração em sibilante (TheStyliS et rapido feSSiS meSSoribuS aeStu em Virgílio; TheStyliS et rubraS meSSibuS uSta genaS, em Marcial). Nota-se que, apesar dos versos conterem informações diferentes, a ambientação quente, de excessivo calor, existente nos versos virgilianos, é retomada no verso 18 do epigrama pela caracterização da personagem como "queimada (usta), nas faces afogueadas (rubras ... genas), (devido ao trabalho) nas messes (messibus)". No epigrama de Marcial, a morenice de Téstilis contrasta com a alvura de Aléxis, assim como o ambiente rústico, campestre e abafado da Buc. 2, no qual se encontra a personagem Téstilis, contrasta com a ambientação "fresca" e algo urbana do cenário de banquete do epigrama, em que o jovem escravo serve o vinho a seu senhor.

Uma vez provido de ajuda material e agraciado com o amor de Aléxis, ambas as graças concedidas, segundo Marcial, pelo patrono Mecenas, Virgílio-Títiro pudera então elevar seu tom e produzir uma obra muito mais grandiosa e importante (19) que o descurado (cf. ore rudi) e rasteiro Culex, composto pouco tempo antes (modo, 20). ${ }^{33}$ Surgiu assim a Eneida, referida com Italiam (provavelmente porque é essa terra que o protago-

\footnotetext{
${ }^{31}$ Tradução de Raimundo Barbosa Nonato de Carvalho.

${ }^{32}$ Cf. também v. 43.

${ }^{33}$ Atribuído a Virgílio, junto de outros poemas, na coleção intitulada Appendix Vergiliana, o Culex teria sido escrito, segundo os comentadores antigos, na juventude do poeta. $\mathrm{O}$ enredo mostra um mosquito que pica um pastor para alertá-lo e salvá-lo de uma serpente que está prestes a dar seu bote. O pastor, no entanto, mata o inseto, cuja alma volta do Hades para recriminar-lhe a ingratidão (cf. A. Schiesaro, OCD, s.v. Appendix Vergiliana, p. 129130). O verbo fleuerat, "chorara" (20), refere-se à morte do mosquito, "chorada" em versos pelo poeta mantuano. Marcial, como se vê no poema que estamos analisando e em Apoph. 185, atribui sem problemas o poemeto a Virgílio (cf. também Estácio, Silv. 1 pref. e 2.7.74).
} 
nista Eneias, no poema, busca alcançar, além de ser o vocábulo que inicia o segundo verso da Eneida) e com as duas primeiras palavras da epopeia, arma uirumque (19). A oposição presente nos advérbios uix/protinus é aí significativa: o deselegante Culex foi composto a duras penas (uix), pois o autor não tinha ainda recebido os benefícios do patrono; já a sublime Eneida nasceu rapidamente (protinus), pois o poeta já contava, então, com o apoio de Mecenas.

Segundo $\mathrm{Izaac}^{34}$, há quem interprete Italiam não como a Eneida, mas como as Geórgicas (Italiam equivaleria, então, ao poema sobre os assuntos relacionados à terra da Itália). Assim, Virgílio teria deixado de lado os gêneros "lusórios" de poesia - Bucólicas, representadas pelas personagens femininas que Virgílio-Títiro "esquece" (excidit) nos versos 17-18, e Culex - para praticar gêneros mais elevados - poesia didática e poesia épica. ${ }^{35}$ Nós, porém, preferimos a primeira interpretação (é o que acaba fazendo também Izaac), na qual Italiam se refere à Eneida, pois os seis versos iniciais e os dois finais do poema parecem tornar essa leitura mais adequada, como veremos a seguir.

No dístico 21-2, Marcial diz não ser necessário ficar enumerando todos os outros poetas felizardos (cf. ditata) - englobados nos plurais generalizantes Varios Marsosque - que receberam apoio de Mecenas e puderam, por isso, praticar tranquilamente sua poesia. ${ }^{36}$ Só o exemplo do grande Virgílio fala por todos. Mas o epigramatista faz, quanto a si próprio, a jocosa ressalva: se receber de um protetor ${ }^{37}$ os mesmos benefícios que Mecenas dera a Virgílio e aos outros poetas de seu círculo, não será um Virgílio, mas um Marso. Ou seja, não será um grande poeta épico, mas um épico medíocre (sabemos, por 4.29.8, que a Amazonis de Domício Marso não era muito apreciada por Marcial).

\footnotetext{
${ }^{34}$ Martial, Épigrammes 2, texte établi et traduit par H. J. Izaac, Paris, Les Belles Lettres, 1933, p. 22, n. 11.

${ }^{35}$ Id., ibid.

${ }^{36}$ Os poetas Vário Rufo e Domício Marso faziam parte do círculo de Mecenas. O primeiro era amigo de Virgílio e de Horácio e teria composto uma tragédia intitulada Thyestes, além de ter sido, segundo a tradição, quem preparou a Eneida para a publicação, após a morte do poeta mantuano (cf. OCD, s.v. Varius Rufus, p. 1581). O segundo era autor de epigramas satíricos, que teria reunido numa coletânea intitulada Cicuta (id.: s.v. Domitius Marsus, p. 493.), o que explica o fato de sempre ser citado por Marcial como um de seus principais modelos (cf. 1 pref. $\S 4,2.71$ e 77, 5.5, 7.99). No epigrama 7.29, Marso também nos é apresentado como escritor de elegias, e, em 4.29, como poeta épico, autor de uma extensa Amazonis.

${ }^{37}$ Talvez o próprio Flaco a quem está se dirigindo (cf. v. 5). Mas cremos que a segunda pessoa em des (v. 24) seja mais bem interpretada como um "tu” genérico.
} 
A nosso ver, existe, nos versos finais do epigrama, uma recusatio, ainda que implícita, do cultivo da poesia épica (o que explica nossa preferência por interpretar Italiam como a Eneida): mesmo que recebesse os mesmos dons que o grande Virgílio recebeu, Marcial seria no máximo um mau poeta épico (como Marso), já que a sua especialidade é outra, a poesia epigramática. Ou, numa interpretação ligeiramente diferente: mesmo que recebesse os mesmos benefícios recebidos por Virgílio, Marcial não seria, tal qual este último, um poeta épico, mas um poeta de epigramas como Domício Marso, que, conforme acabamos de frisar em nota, é citado frequentemente, pelo poeta de Bílbilis, como um de seus principais modelos no gênero epigramático. Nessa segunda interpretação, a referência a Marso seria, evidentemente, positiva: Marcial, com o auxílio recebido, seria, como Marso, um bom poeta de epigramas. Mas, independentemente de qual das duas leituras se $\operatorname{adote}^{38}$, o que se tem, em suma, é a recusa de Marcial em cultivar a poesia épica, na qual não se sairia bem mesmo que gozasse do mesmo apoio recebido pelo grande poeta épico da literatura latina. Apesar de os feitos bélicos da época e do principado de Domiciano serem, segundo o epigramatista, superiores aos da era de Augusto (cf. 1-2) e de merecerem um vate que os celebre tão extraordinariamente quanto fizera Virgílio na Roma augustana (3-4), não será ele, Marcial, quem cantará a grandeza da Roma do presente, pois, sendo um poeta de epigramas, não tem talento e inspiração para tão importante e sublime tarefa. ${ }^{39}$

Mas voltemos às Bucólicas para resumirmos nossas conclusões, já anunciadas aqui e ali. Quais efeitos de sentido os vários intertextos com as éclogas virgilianas, os quais identificamos nas páginas anteriores, trazem para a leitura do epigrama de Marcial?

O principal efeito de leitura, a nosso ver, é a construção, por meio desses intertextos, de uma "biografia" de Virgílio segundo a qual toda a grandiosidade de sua poesia se deveu ao apoio recebido de seu patrono. Marcial, então, usa o exemplo de Marão para provar a tese de que tal apoio é imprescindível no surgimento de grandes obras literárias, bem como para criticar a decadência do mecenato no final do século I d.C.

\footnotetext{
${ }^{38}$ Aliás, pode-se mesmo adotar simultaneamente as duas: Marcial se tornaria um Marso por ser, a um só tempo, mau poeta épico e bom poeta epigramático.

${ }^{39}$ No corpus de Marcial, muitos outros epigramas tematizam a oposição poesia epigramática vs. poesia épica, ou, de forma mais geral, gêneros "baixos" vs. gêneros "elevados". Alguns desses poemas se constituem em recusationes, por vezes explícitas, por vezes implícitas, como no epigrama que acabamos de analisar. Cf. Apoph. 1 e 185; 4.14 e 49; 5.30; 8.3; 9.50 e $90 ; 10.4,35.1-9$ e 64 ; e 12.94 .
} 
No enredo da vida de Virgílio tendenciosamente construído, dados biográficos são extraídos, alusivamente, das Bucólicas 1, 2 e 9 (sem se desprezar as alusões menos diretas, por meio da reutilização de nomes próprios, às outras éclogas), promovendo a fusão de quatro figuras bucólicas - Títiro, Menalcas, Melibeu e Córidon - num único personagem, nomeado "Títiro" no epigrama e identificado com o próprio poeta Virgílio. A fusão mostra a liberdade com que o material emprestado é usado no novo contexto: não há preocupação com o pertencimento de cada elemento ou característica a cada um dos quatro personagens de Virgílio; o que interessa a Marcial é usar todos esses elementos, livremente, para criar a imagem de um pastor expropriado de suas terras que foi ajudado materialmente por um protetor e pôde, consequentemente, cultivar sua musa e compor uma grande obra-prima.

O leve humor presente na recusatio do dístico final do epigrama também deve algo à biografia virgiliana forjada por Marcial através das alusões às Bucólicas. Segundo o epigramatista, a biografia construída e o exemplum virgiliano poderiam levar a concluir (cf. ergo, 23) que ele, Marcial, se tornaria tão bom quanto Virgílio, caso recebesse os munera Maecenatis ("os benefícios de Mecenas"). Afinal, de acordo com a relação de causa e consequência construída, Virgílio-Títiro só teria se tornado um grande poeta graças a esses benefícios. O próprio Marcial, entretanto, se apressa em corrigir, jocosa e modestamente, a conclusão: ele jamais seria um Virgílio, mas apenas um Marso, um mau poeta épico, ou, ainda, nem seria um poeta de tal gênero, já que cultiva musas mais ligeiras. O que não o impede de desejar para si o mesmo tipo de patrocínio de que gozara Marão e os outros escritores do círculo de Mecenas. Todos os poetas, de todos os gêneros de poesia, necessitam, para o pleno desenvolvimento de sua atividade criativa, do otium "que Mecenas concedera outrora a Flaco e ao seu Virgílio".

TitLE. Virgil's Eclogues and Martial 8.55: intertextuality, patronage and an implicit recusatio

ABSTRACT. This paper analyzes the strong intertextual elements that relate Martial's epigram 8.55 to the Virgil Eclogues, especially Eclogues 1,2 and 9. By incorporating these elements of form and content borrowed from Virgilian poems, Martial builds, in this ingenious metapoetic epigram, a "biography" of the poet from Mantua very useful in defending the idea that material support is necessary for writers to produce great works of literature; at the same time, through a recusatio which is implict in the last lines of the epigram, Martial addresses the issue of the poetic genres and justifies, as in many other passages of his work, his choice of slight poetry.

KEYwords. Martial; epigram; Virgil; Eclogues; intertextuality; patronage; recusatio. 